\title{
Pragmatic White Allyship for Higher Education Popular Music Academics
}

\author{
Jason Huxtable \\ Leeds Arts University \\ jason.huxtable@leeds-art.ac.uk
}

\begin{abstract}
The world watched the killing of George Floyd from a position of COVID induced captivation. The succeeding global protests and Black Lives Matter movement justly prompted us all to consider our own complicity with the modes of systemic racism which have normalized anti-Black thought and action. The Wonkhe@Home: Black Lives Matter event (July 2020) sought to share pragmatic advice for 'taking action to tackle racism across $\mathrm{HE}^{\prime}$, aware of the responsibility for the Higher Education sector to acknowledge its own role in consecrating racist forms of knowledge. This 'statement' translates session outcomes for Popular Music Academics (PMA), provoking the ethical imperative to reflect upon individual situational praxis towards White Allyship action. Through consideration of PMA's typical fields of agency, I make suggestions towards development of anti-racist learning cultures within Popular Music Higher Education.
\end{abstract}

KEYWORDS: Higher Education, anti-racism, White allyship, praxis

\section{"Why now?"}

"Why now," provoked Paulette Williams. "Why Now" are, previously quiet, White voices signaling the discourse-markers of Anti-Racism? This was one of the most penetrative moments of the Wonkhe@Home: Black Lives Matter event in July 2020. This session sought to provide opportunities for Higher Education (HE) leaders, administrators and academics to share pragmatic advice for 'taking action to tackle racism across $\mathrm{HE}^{\prime}$ (Wonkhe 2020).

Paulette spoke directly to me. "Why now" had I taken the time to attend this event? What were my motives? Her skepticism of this latest wave of White allyship spoke to a continued experience of potentially well-meaning but, ultimately, hollow White 'slack-tivism': performative virtue signaling vying for peer approval, fashion conscious of the need to be seen and heard. This was a challenging question which caught attention in session reporting (McVitty 2020). Paulette's provocation 
required action. Not aloof 'discussion', safely cocooned within the (White) ivory tower of academia, but action, pragmatically situated in the here and now.

"Why Now?" The year 2020 beheld us in witness of George Floyd's murder from a position of stillness and attention. The visceral injustice of police brutality played to a captive audience held still by the COVID-19 pandemic. This was not only a killing made by racist police but by a racist society, complicit in promoting the conditions for toxic racism to fester, grow and unleash.

The rise of racist thought and action had been gathering pace over the last few years. The visibility and power of far-right racism had reached its apex of normalisation in Donald Trump's presidency. In Europe, increases in hate crimes and racially motivated abuse overflowed with increased frequency and aggression. As statues of colonists were toppled on the streets of the UK, Black British citizens, the 'Windrush Generation', were deported, echoing the 'hostile environment' rhetoric of the UK government. Weekly killings in major UK cities provided an unrelenting, numbing news reel of Black death. These events, exacerbated by COVID-19, revealed the intensifying symptomatic responses to society's terminal illness of systemic racism.

COVID has been destructive, deadly and devastating but also, hopeful. This time of isolation and reflection has focused global attention on modes of systemic discrimination which conspire to reinforce cultural cruelties. The ever-increasing inequalities idealized through faux meritocratic, 'common-sense', neoliberalist, wealth over health, 'post-racist' ideology have been discharged through seismic collisions between powerful forces of exploitative domination and the rapid unveiling of injustices present in the lived experience of Black society for all to see. The COVID pandemic provided conditions for reflexivity but pure reflection is insufficient for change to come.

\section{Situational Praxis}

A Critical Praxis, as Freire teaches (1970), necessarily contains both reflection and action. Reflection without action renders us impotent verbalists, capable of recognizing our own complicities but lacking the bravery to truly change our/the world through action. An effective praxis is where action necessarily manifests within our own situation, our unique position in space and time, responsive to the opportunities and cultural capital we possess. We can only act from where we stand, not where we may wish to be or when 'conditions are right'.

As educators we can also be(come) de-educators. Racism has been learned and it can be unlearned. Educators are well placed to problem-pose these matters of enculturation, unveiling the shadow aspect of a broken society towards personal transformations and emancipation. 'The only remedy to racist discrimination is antiracist discrimination' (Kendi 2019). As educators, especially within popular music, we reside in a unique position, one that comes with much possibility and potential influence and, therefore, responsibility.

So what, as Popular Music Academics (PMAs) in HE, can be done within our departments, curriculums, institutions and professional fields of influence to address this critical moment. What are our responsibilities towards our learning communities and how should these be enacted? What are we willing to risk to transform our learning cultures from racist to anti-racist? How could I translate the suggestions within the Wonkhe session towards pragmatic, action based, outcomes relevant for PMAs in $\mathrm{HE}$ ? 
To address these questions, and to translate them towards a PMA context, I am using transcribed excerpts spoken by contributors at the event. There is an ethical imperative to amplify Black voices. The recording of the event can be accessed at https://www.youtube.com/watch?v=-dG9SfhMYe8 and excerpts are time labelled (Leach 2020). Full contributors' biographies are found on the event website (Wonkhe 2020). As means of accreditation I will use this coding method: (AD)Amatey Doku, (JA)Jason Arday, (PW)Paulette Williams, (HG)Hilary GyebiAbabio, (MH)Marilyn Holness, (RW) Randall Whittaker.

\section{Responsibility}

Educators of all disciplines have a responsibility to act, particularly White academics. Black academics are under-represented in UK learning communities with latest statistics showing only $2 \%$ of academic staff as Black (HESA 18/19). Black academics become even scarcer at Professorial level, less than $1 \%$ of UK professors. There is a lack of presence of Black voices in academic decision making, particularly as influence increases. White academics, of all levels of influence, have a responsibility to speak.

JA(30.21) We have always left people of colour...to deal with issues of racism, even though in many cases they don't have the power or privilege to absolve themselves of that situation.

HGA(1.27.07) It should never be expected for Black people to come up with the solutions to their own oppression

RW(2.04.45) ... leaders need to reflect on the privileges they enjoy because they are White and think through how they can use their privilege to address systemic racism.

\section{White Allyship}

In the absence of an equality of representation within our academic communities, it is incumbent on White academics to work as allies. There are multiple interpretations of what this could mean but, firstly, it should center on lightening the load for Black staff and students, championing and advocating for them.

PW(39.00) Black people are leading this work and we're tired and they're removing some of that labor for us which is amazing.

How to be an effective White ally? Firstly, listen to Black students and colleagues. How can we help?

$\mathrm{MH}(1.37 .06)$ we need to know about the lived experiences of those people which these terms refer to (BAME, Black)... (1.39.06) we need to know our students and their lived experiences...Who are they, what are their drivers, what are their barriers, what are their aspirations...

Popular Music has its essence in the storytelling of personal narratives. If we want to know our students, their lived experiences and unique situationalities, whilst also 
developing their creative and technical skills, set study briefs which provoke a personal response. Rather than writing 'in the style of' or 'for industry brief' we can encourage students to write about themselves: write a protest song, write about 'identity', write music which relates to you. What is Popular Music if not the communicative action of narrative discourse? Exploring and communicating the stories of self can become central to the process of all our students discovering, and becoming, themselves.

Institutionally, White allies should be vocal in endorsing the expertise present in Black colleagues and students, recommending them for new projects, opportunities and roles. It is more pragmatic to promote existing voices as a step towards systemic change than to tackle larger scale recruitment barriers. We can champion Black voices from industry, using departmental budgets to invite speakers for masterclass events. This confidence to 'speak up' can also be harnessed to challenge racist micro-aggressions which compound to normalize a culture of silence.

JA(28.54) when I talk about that complicity, how much are we aware of? How much do we turn a blind eye to these situations. When we think about this, we are reconceptualizing what Allyship looks up. Giving up privilege is a huge part of acknowledging it, in recognizing that there are differentials in the first place which don't reside within the idea of Meritocracy.

These anti-racist interventions must be reinforced through a robust reporting structure and transparent reporting system. Goldsmiths (Akel 2019), for example, have led the way in publishing findings that $26 \%$ of BME students 'reported experiencing racism from students and staff members' and 'an additional $43 \%$ have experienced racialized microaggressions'. The magnitude of these findings indicates how commonplace abuse exists within our institutions. To fail to investigate is to White-wash. If reporting mechanisms are unclear, challenge institutional leaders.

HGA (1.54.03) Institutions are talking about culturally competent cares, report and support mechanisms which, quite frankly, I don't know if I've come across a genuinely robust one in terms of reporting racism.

\section{Decolonization of Curriculum}

Where PMAs typically have most agency is decisions around curriculum. Often curriculum is understood as what is taught, and it is, but also incorporates the pedagogy which informs the method of teaching and what is not taught; the hidden curriculum.

$\mathrm{AD}(6.27)$ Universities have played a critical role in the creation of race as a concept.

$\mathrm{JA}(27.56)$ Universities in many ways are actually worse than some other institutions in terms of race equality and having penetrative interventions that really tackle and address racism in all of its systemic, cultural and insidious forms.

Decolonization of curriculum is not only important from the perspective of White allyship but also acknowledges the University's role in consecrating the 
knowledge and philosophical underpinnings of White, colonial, imperialist thought. Black history, struggle and suffering are not unrelated components of Popular Music - they are central. However contested the term 'Popular Music' is ontologically, the impact of the transatlantic slave trade on the evolution of Popular Music is undeniable. To what extent are we making this history explicit and how central are the cultural contexts of the musical objects we explore within our practice?

HGA(1.28.54) We need to expand decolonisation work outside of just EDI team...decolonisation in itself is a transformational process which needs to be institution wide, not piece-meal

Decolonization of Curriculum is not a tokenistic or 'easy' activity. It is insufficient to just add extra repertoire to be studied: "It is more than having some smiling Black faces on your prospectus or your website" AD(9.42). It is a Praxis of re-examining the biases, assumptions and historical norms which infuse what is taught and how. Music as a cultural constituent is present within all social events and interaction. As PMAs we can anchor our pedagogy in a critical examination of these cultural contexts. For example, George Floyd, AKA Big Floyd, was a proponent of Houston's Chopped and Screwed hip-hop scene, a hip-hop subgenre developed by DJ Screw in the early 90s. An investigation into the intersectionality between Chopped and Screwed aesthetics, hip-hop stylistic function, Black struggle and police brutality would be an interesting musicological route towards students' habitually investigating their world through the lens of musical praxis.

Course validation and periodic review processes are also a vital opportunity to re-evaluate the 'Whiteness' of our curriculum and pedagogy. Does our curriculum, pedagogy and network of subject specialists really reflect the epistemological authority of Black voices when addressing the meanings and communication of Popular Musical forms?

RW(2.06.21) What is going wrong in your periodic review or course approval processes for your curriculum still to be White?

\section{Access}

Higher Education music departments are, unfortunately, impotent against the systemic dismantling of publicly funded music education, music activity in schools and access to musical experiences for all but the privileged. Institutional Access and Participation plans can, however, be an effective way of integrating our ethical responsibility as educators to institutional targets.

$\mathrm{MH}$ (1.56.04) The Access and Participation plan is crucial. The targets in the plan should be known and owned by everybody in the university.

Our powerlessness to alter the national situation can be tempered by our ability to modify and contextualize our entry requirements, helping prospective Black students understand how they meet those entry requirements. To what extent are we narrowing the range of individuals who may wish to apply through rigid insistence on forms of institutional capital reserved for those of privilege (for 
example, formal music theory qualifications, instrumental grade success and Alevel attainment).

There is an intersectionality between wealth and ethnicity and when we demand formal qualifications, conditional on capital, we exclude. We do not 'dumb down' entry requirements when we work towards new cultures of understanding where a wider range of musical skills can be recognized as valuable, taking the particular contexts of applicants into consideration. If we want all our students to benefit from learning environments which reflect the diversity of our communities, an accessible music industry and a peaceful social landscape we need to work together to address systemic exclusion of young Black musicians.

RW(2.09.32) Being aware of racism does not fix racism. Now that the momentum of the Black Lives Matter protest and social media outrage has been lost, will you be speaking out about racism? Will you still be an ally; remember you can do better, keep the conversation going.

\section{References}

\section{Bibliography}

Akel, S. 2019. INSIDER-OUTSIDER: The Role of Race in Shaping the Experiences of Black and Minority Ethnic Students.

https://www.gold.ac.uk/media/docs/reports/Insider-Outsider-Report-191008.pdf Accessed: 03 January 2021.

Freire, P. 1970. Pedagogy of the Oppressed. New York: Seabury Press.

HESA 2018/2019. Who's working in HE? Personal characteristics.

https://www.hesa.ac.uk/data-and-analysis/staff/working-in-he/characteristics

Accessed: 03 January 2021.

Kendi, I.X. 2019. How To Be An Antiracist. London: The Bodley Head.

McVitty, D. 2020. White people must commit to antirascist action for the long term. https://wonkhe.com/blogs/white-people-must-commit-to-antiracist-actionin-the-long-term/ Accessed: 03 January 2021.

\section{Web Sources}

Wonkhe. 2020. Wonkhe@Home: Black Lives Matter. https://wonkhe.com/events/wonkhe-home-black-lives-matter/ Accessed 30 December 2020.

\section{Videography}

Leach, Mark 2020. Wonkhe @ Home - Black Lives Matter (Online video). Available at: https://www.youtube.com/watch?v=-dG9SfhMYe8. Accessed 9 August 2021. 